\title{
Strengthening of Top-Down Frontal Cognitive Control Networks Underlying the Development of Inhibitory Control: A Functional Magnetic Resonance Imaging Effective Connectivity Study
}

\author{
Kai Hwang, ${ }^{1,2}$ Katerina Velanova, ${ }^{2,3}$ and Beatriz Luna ${ }^{1,2,3}$ \\ ${ }^{1}$ Department of Psychology, ${ }^{2}$ Center for the Neural Basis of Cognition, and ${ }^{3}$ Department of Psychiatry, University of Pittsburgh, Pittsburgh, \\ Pennsylvania 15213
}

The ability to voluntarily inhibit responses to task-irrelevant stimuli, which is a fundamental component of cognitive control, has a protracted development through adolescence. Previous human developmental imaging studies have found immaturities in localized brain activity in children and adolescents. However, little is known about how these regions integrate with age to form the distributed networks known to support cognitive control. In the present study, we used Granger causality analysis to characterize developmental changes in effective connectivity underlying inhibitory control (antisaccade task) compared with reflexive responses (prosaccade task) in human participants. By childhood, few top-down connectivities were evident with increased parietal interconnectivity. By adolescence, connections from prefrontal cortex increased and parietal interconnectivity decreased. From adolescence to adulthood, there was evidence of increased number and strength of frontal connections to cortical regions as well as subcortical regions. Together, results suggest that developmental improvements in inhibitory control may be supported by age-related enhancements in top-down effective connectivity between frontal, oculomotor, and subcortical regions.

\section{Introduction}

Although core cognitive functions are online early in development (Diamond, 1989; Diamond and Goldman-Rakic, 1989), control functions that support mature goal-directed behaviors show continued refinement through adolescence into adulthood (Luna et al., 2001, 2004). A well characterized distributed neural network is known to support mature inhibitory control, including the anterior cingulate cortex (ACC), the inferior frontal gyrus (IFG), the dorsal lateral prefrontal cortex, the frontal eye field (FEF), the posterior parietal cortex, the striatum, and the cerebellum (Rubia et al., 2003; Curtis et al., 2005). Previous studies have characterized immaturities in the function of segregated brain regions in this circuitry (Casey et al., 1997; Luna et al., 2001; Bunge et al., 2002; Durston et al., 2002; Rubia et al., 2007; Velanova et al., 2008, 2009). However, there are known brain processes that underlie the integration of functions across regions (Luna et al., 2010). For example, the continued myelination of axons beyond early childhood (Yakovlev et al., 1967; Paus et al., 1999) and synaptic pruning (Huttenlocher, 1979; Rakic et al., 1986) enhance the efficiency of neuronal transmission throughout distributed circuitries (Olesen et al., 2003; Boorman et al., 2007;

Received April 14, 2010; revised Sept. 14, 2010; accepted Sept. 20, 2010.

This research was supported by National Institute of Mental Health Grants R01 MH067924 and K01 MH082123.

Correspondence should be addressed to Kai Hwang, Laboratory of Neurocognitive Development, Loeffler Build-

ing, Room 108, 3811 0'Hara Street, University of Pittsburgh, Pittsburgh, PA 15213. E-mail: kah124@pitt.edu.

DOI:10.1523/JNEUROSCI.2825-10.2010

Copyright $\odot 2010$ the authors $\quad 0270-6474 / 10 / 3015535-11 \$ 15.00 / 0$
Stufflebeam et al., 2008). Furthermore, resting state functional connectivity magnetic resonance imaging (rs-fcMRI) studies have shown that functional connectivity between distant regions increases with age (Fair et al., 2007, 2009). These findings indicate that intrinsic functional organization has a protracted development.

It is still unclear, however, how these intrinsically integrated circuits behave across development during active cognitive processing. Individuals must be able to actively reconfigure functional interactions between distributed regions under different behavioral contexts. For example, during selective attention, topdown modulation between frontal, parietal, and occipital regions increases to facilitate information processing (Bressler et al., 2008). In contrast, when processing unexpected but salient stimuli, bottom-up signals are transmitted from the parietal cortex to the frontal cortex (Buschman and Miller, 2007). In the case of inhibitory control, how top-down modulation and basic sensory-relay processes (i.e., effective connectivity) that support cortical-cortical and cortical-subcortical communications become established in adulthood is not well understood. In the current study, we used Granger causality analysis (GCA), an effective connectivity method that allows the estimation of directionality between functional regions (Roebroeck et al., 2005; Bressler and Seth, 2010), to characterize the development of top-down and bottom-up connectivity underlying inhibitory control.

Our aims were to delineate the effective connectivity supporting inhibitory control and to characterize its development. We measured effective connectivity between functional regions while subjects performed an inhibitory control task, the antisaccade 
task (AS) (Hallett, 1978), and a basic oculomotor task, the prosaccade task (PS). Given evidence for continued improvements in inhibitory control through adolescence (Luna et al., 2004), known changes in white matter connectivity (Paus et al., 1999; Asato et al., 2010), as well as the effect of top-down modulation on cognitive control (Miller and Cohen, 2001), we predicted that frontal to oculomotor and subcortical top-down connectivity would show protracted development.

\section{Materials and Methods}

\section{Participants}

Ninety-eight individuals aged 8-27 years participated in the study. Twenty participants ( 9 children, 10 adolescents, and 1 adult) were excluded as a result of equipment failure, noncompliance, or artifacts/noise in the imaging data. Thus, we report data from 78 participants, including 26 children (aged $8-12$ years, 11 males and 15 females), 25 adolescents (13-17 years, 10 males and 15 females), and 27 adults (18-27 years, 11 males and 16 females). We defined age groups based on our past behavioral studies indicating differential cognitive performance on the antisaccade task (Luna et al., 2004). All participants were native English speakers with no history of neurological or psychiatric conditions in themselves or a first-degree relative as established by interview. All had normal or corrected-to-normal vision. All had normal full-scale intelligence quotients, and these did not differ significantly across age groups. Naive participants spent $\sim 15 \mathrm{~min}$ in a mock scanner to acclimate them to the MR environment before entering the research scanner. Experimental procedures for this study complied with the Code of Ethics of the World Medical Association (1964 Declaration of Helsinki) and the Institutional Review Board at the University of Pittsburgh. Subjects or their guardians provided informed consent, and subjects were paid for their participation. Functional MRI (fMRI) data from these subjects, analyzed using conventional procedures, has been reported in previous publications from our laboratory (Velanova et al., 2008, 2009).

\section{fMRI data acquisition}

Data were acquired using a Siemens 3 tesla MAGNETOM Allegra scanner with a standard head coil. Pillows and tape were used to minimize head movement. Stimuli were viewed via a mirror attached to the head coil that reflected images projected onto a screen at the head of the scanner bore. Structural images were acquired first using a sagittal magnetization-prepared rapid gradient-echo T1-weighted sequence [repetition time (TR), $1570 \mathrm{~ms}$; echo time (TE), $3.04 \mathrm{~ms}$; flip angle $(a), 8^{\circ}$; inversion time, $800 \mathrm{~ms}$; voxel size, $0.78125 \times 0.78125 \times 1 \mathrm{~mm}]$. Functional images were then acquired using an echo-planar sequence sensitive to blood oxygenated level-dependent (BOLD) contrast (T2*) (TR, $1.5 \mathrm{~s}$; TE, $25 \mathrm{~ms} ; a=70^{\circ}$; voxel size, $3.125 \times 3.125 \mathrm{~mm}$ in-plane resolution; 29 contiguous $4 \mathrm{~mm}$ slices). Participants performed four functional runs (each lasting 6 min $15 \mathrm{~s}$ ), followed by up to three runs of an unrelated experiment. The first six images in each run were discarded to allow stabilization of longitudinal magnetization.

\section{Behavioral tasks}

The study was conducted as a mixed block/event-related design (Visscher et al., 2003). In each run, participants alternated between blocks of AS performance, blocks of PS performance, and extended periods of fixation. Specifically, each run started with a block of $36 \mathrm{~s}$ (24 volumes) of fixation (control), followed by a $118.5 \mathrm{~s}$ task block (during which participants performed the AS or PS task; 79 frames), a second block of fixation (48 s; 32 MR volumes), a second task block (118.5 s; 79 MR volumes), and a final block of fixation ( $39 \mathrm{~s} ; 26 \mathrm{MR}$ volumes). The order of tasks was counterbalanced across runs (within participant) and randomized across participants. An instruction screen was presented for $3 \mathrm{~s}$ at the beginning of each task block to inform participants of the type of block that was about to begin (either "Start LOOK-AWAY game" for AS blocks, or "Start LOOK-TOWARD game" for PS blocks). Within AS and PS task blocks, the duration of intervals between task trials was jittered. For AS trials, participants were instructed to look to a point on the screen opposite the location of a peripheral target stimulus. For PS trials, participants were instructed to look toward the target stimulus. Each task block (AS and PS) consisted of 12 trials, with a total of 48 AS and 48 PS trials across runs. Each trial began with a $3 \mathrm{~s}$ fixation crosshair (subtending $\sim 0.7^{\circ}$ of visual angle). The crosshair color could be green, cueing participants to make a prosaccade, or red, cueing an antisaccade. Each target stimulus was a solid yellow circle, subtending $\sim 0.5^{\circ}$, and was presented on the horizontal meridian at one of six unpredictable eccentricities (at $\pm 3,6$, or $9^{\circ}$ ). Fixation periods between trials varied from 3 to $9 \mathrm{~s}$ (two to six volumes). Each task block ended with a 3 s "task end" cue, indicating that a long period of fixation would follow.

\section{Eye tracking}

A long-range optics eye-tracking system (model R-LRO6; Applied Science Laboratories) was used to obtain eye movement measurements in the scanner. Nine-point calibration was conducted immediately before scanning, during which subjects were asked to fixate on points on a $3 \times$ 3 grid. Eye movements were scored offline using ILAB (Gitelman, 2002) and an in-house scoring suite. The proportion of times when eye movements were made to correct locations and latencies to initiate correct responses were measured. Correct saccades were identified as eye movements with velocities exceeding $15 \%$ toward the correct direction and with latency $>67 \mathrm{~ms}$.

\section{Imaging data analysis}

Our analysis stream consisted of three stages: (1) regions of interest (ROIs) selection, (2) effective connectivity analysis using GCA, and (3) functional connectivity analysis (FCA). First functional imaging data were preprocessed and analyzed with the general linear model (GLM) (Friston et al., 1995) to identify brain regions significantly activated by the AS task. Significant peaks known to be associated with oculomotor and cognitive control were selected as ROIs for connectivity analyses. Functional time series were extracted from each ROI. We then applied GCA and FCA to functional time series to delineate the connectivity profile underlying inhibitory control across different age groups.

Regions of interests selection. Regions of interest were defined in a twostep manner by first empirically identifying task-related activity in the present dataset and subsequently further defining areas in a hypothesisdriven manner. First, we used a GLM to identify activated peaks that showed significant signal modulations of AS trial activity estimates. List of activated peaks were obtained for each age group using GLM procedures outlined by Velanova et al. (2008). Peaks were defined separately for each age group to allow for the possibility that different age groups could use a different set of regions to accomplish the task. To delineate the circuitry associated with oculomotor and cognitive control in a hypothesis-driven manner, we compared ROIs generated from the coordinates of our activated peaks with a theoretically defined template. The template consisted of peaks based on our groups' previous finding on the development of oculomotor control/response inhibition (Luna et al., 2001) and two meta-analyses reports on general cognitive control processes (Dosenbach et al., 2006, 2007). We also highlighted subcortical regions and the ACC, a region well characterized subserving cognitive monitoring processes (Carter et al., 1998; Rushworth et al., 2004; Velanova et al., 2008). Activated peaks within $10 \mathrm{~mm}$ radius of template peaks were selected as ROIs (Fig. 1). For each age group, ROIs were created by generating 8-mm-radius clusters around these selected peaks.

Effective connectivity analysis. Granger causality is an effective connectivity method that quantifies the improvement in predicting the signal of one brain region that results from inclusion of the signal of another region into the prediction (Roebroeck et al., 2005; Bressler and Seth, 2010). This method could potentially provide estimates of the strength and directionality of information flow between brain regions during active tasks. Unlike structural equation modeling approaches such as dynamic causal modeling (Friston et al., 2003), which requires that one make assumptions about the existence of connectivity between selected regions, GCA is model free and data driven. For our study, a model-free approach is optimal because the developmental differences in brain connectivity underlying inhibitory control processes have not been established. GCA is often prematurely dismissed because of the sluggish nature of the BOLD signal, and GCA aims to assess neuronal transmission that occurs at a much faster rate than the sampling rate of fMRI. 
However, evidence exists to suggest that fMRI can successfully identify sequences of cognitive processes (mental chronometry) when neuronal events are separated by at least 100-200 ms (Menon et al., 1998). Furthermore, the ability for GCA to detect neuronal interactions in fMRI data has been demonstrated in a study that simulated fMRI data by convolving standard canonical hemodynamic response functions with local field potentials recorded from the macaque cortex (Deshpande et al., 2010). Results showed that data collected using a $1.5 \mathrm{~s}$ TR (sampling rate) reliably detected neuronal delays of $300-400 \mathrm{~ms}$. In the antisaccade task, human and primate electrophysiology studies show peak activation at $\sim 180 \mathrm{~ms}$ after stimulus cue onset in frontal cortex (Clementz et al., 2007) with downstream subcortical activity that continues to peak until the saccade onset (Ford and Everling, 2009). In our paradigm, subjects are cued $3 \mathrm{~s}$ before presentation of the target stimulus. This results in a time lag between cue and saccade onset that is longer than $400 \mathrm{~ms}$, providing a feasible temporal resolution for GCA. We acknowledge that neural interactions associated with control processing are likely occurring at a timescale under $300 \mathrm{~ms}$ (Ringo et al., 1994; de Pasquale et al., 2010), and GCA cannot reliably detect these connections. In contrast, correlational connectivity analysis such as FCA does not rely on temporal precedence to detect connectivity patterns and should be more sensitive to these fast interacting connections. Thus, we also performed FCA to capture these fast interacting connections, acknowledging that both FCA and GCA cannot uncover the directionality of these connections.

We adopted several approaches to optimize our GCA. First, because GCA can produce spurious false positives when considering a unidirectional influencing term, we calculated the differenced influence term (DOI) (the degree of $x$ influencing $y$ - the degree of $y$ influencing $x$ ). DOI reflects the "dominant" effective connectivity strength and direction between ROIs (Roebroeck et al., 2005). Because DOI only measures "dominant" influencing direction between ROIs, it cannot detect reciprocal causal connectivity in which effective connectivity strength is symmetrical in both directions. Second, because the hemodynamic delay may not be uniform across the brain (Handwerker et al., 2004), differences in hemodynamic properties across ROIs could bias the GCA results (Chang et al., 2008; David et al., 2008). We addressed this limitation by contrasting DOIs across different tasks (AS and PS). Connections that are modulated by task condition should be reliable, given that the hemodynamic delay is unlikely to change across conditions. Furthermore, connections that were significantly greater for AS when compared with PS are more likely associated with active inhibitory control processes because basic perceptual and oculomotor processes are equivalent between AS and PS. Contrasting DOIs across conditions has the advantage of minimizing false positives and controlling for hemodynamic inhomogeneity, but DOI can only detect asymmetrical effective connectivity and comes with the cost of missing reciprocal connections. A DOI of AS > PS can indicate that effective connectivity strength from one region to another is stronger for AS compared with PS, or effective connectivity strength is more asymmetrical for AS compared with PS. Finally, we note that concerns regarding possible developmental differences in neurovascular coupling have now been well addressed. A seminal paper has indicated that the hemodynamic response is equivalent across ages throughout different brain regions while performing different types of tasks (Kang et al., 2003).

In the current study, GCA was performed based on methods described by Roebroeck et al. (2005), Sridharan et al. (2008), and Duann et al. (2009). First functional imaging data were preprocessed to remove noise and artifacts. Preprocessing steps included slice timing correction, motion correction, and spatial normalization into a standardized Talairach template (Talairach and Tournoux, 1988). Then nuisance variables were removed from preprocessed images by regression of the following variables: six-parameter rigid-body head motion, signals averaged over the lateral ventricle masks, and white matter ROIs. Ventricle and white matter masks were created using Freesurfer (Fischl et al., 2002). Residual images were converted into percentage signal change. Mean block time series from the 14th to the 79th images of each AS block and PS block were extracted from each ROI across all subjects. The first 13 images were excluded before applying the model to prevent the instructional task-cue onset effect (Konishi et al., 2001; Dosenbach et al., 2006) from contam-

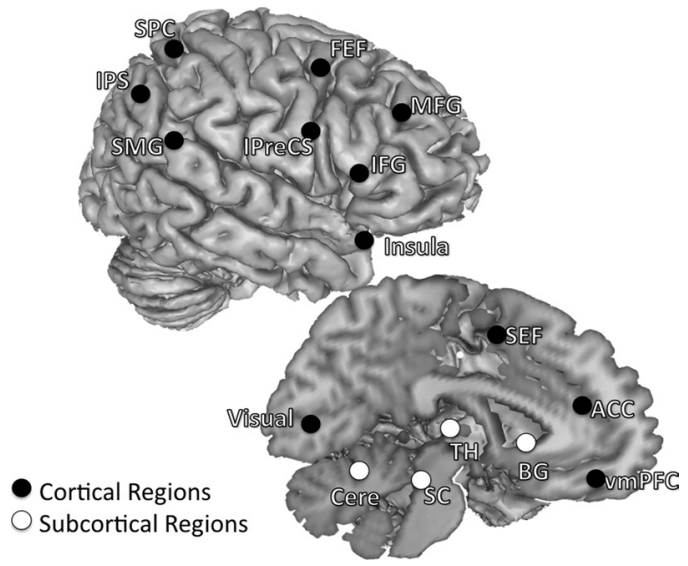

Figure 1. Regions selected as ROls. Both left- and right-hemisphere regions are placed on the right hemisphere to aid with visualization, and coordinates of each ROl are listed in Table 1. Twenty-six regions known to be involved in oculomotor control/response inhibition (Luna et al., 2001) and general cognitive control processes (Dosenbach et al., 2006, 2007) were selected. These regions can be sorted into different functional subgroups based on published literatures and their anatomical locations. We specified ROls that comprised the oculomotor circuitry, including the SEF, bilateral FEF, bilateral IPreCS, bilateral IPS, bilateral SPC, and bilateral SMG (Luna et al., 1998, 2001; Berman et al., 1999; Merriam et al., 2001). We also identified several cognitive control regions in the frontal cortex associated with task control (Müri et al., 1998; Dosenbach et al., 2006, 2007), attentional processes (Corbetta and Shulman, 2002; Bressler et al., 2008), working memory (Curtis and D'Esposito, 2003), and response inhibition (Aron et al., 2004), including the right MFG, right IFG, and bilateral insula. The ACC was included because of its association with monitoring the consequences of actions or conflicts between motor responses (Paus et al., 1993; Carter et al., 1998; Braver et al., 2001; Rushworth et al., 2004). Subcortical regions included bilateral putamen (denoted as BG for basal ganglia), bilateral dorsal medial thalamus (TH), the SC, and the cerebellum (Cere), and these are also known to be involved in the inhibitory control of saccades (Sweeney et al., 1996; Müri et al., 1998; Luna et al., 2001). Abbreviations apply to all figures.

inating the effects of interest. Thus, each subject provided 4 blocks $\times 26$ ROIs $=104$ time series per condition (two conditions of AS and PS), with each time series consisting of 66 time points. Task blocks with excessive head motion were excluded from additional analyses. Measures of head movement were obtained from the output of the rigid-body rotation and translation algorithm. Translations and rotations in the $x, y$, and $z$ dimensions were averaged across frames, and total root mean square (RMS) linear and angular precision measures were calculated for each run. Blocks in which a participant's total RMS movement exceeded $1 \mathrm{~mm}$ or degree were discarded.

After excluding block time series with excessive head motion, 15,652 time series were analyzed. Time series were checked for covariance stationary with the augmented Dickey Fuller test (Hamilton, 1994), a necessary assumption for GCA. Ninety-nine time series were nonstationary and therefore excluded and treated as missing values in subsequent analyses. Time series were then imported into MATLAB for GCA, using the Causal Connectivity Toolbox (Seth, 2010). For each subject, bivariate Granger causality was assessed for each ROI pair and for each block separately. The order of the autoregressive model was selected using the Bayesian information criterion (Schwartz, 1978). The Bayesian information criterion selected low model orders ( 1 or 2$)$ for the majority of the autoregressive models (Roebroeck et al., 2005) (supplemental Fig. 1, available at www.jneurosci.org as supplemental material). For model validation, we performed the statistical consistency test (Ding et al., 2000) to assess the portion of the data captured by the autoregressive model, and results showed that the autoregressive model adequately captured the data (supplemental Fig. 2, available at www.jneurosci.org as supplemental material). We calculated the DOI of each block, took the median within each subject, and submitted the median DOI to group analyses.

For each ROI pair, we calculated the median DOI of each age group and performed statistical inference analyses using bootstrapping proce- 
Table 1. List of regions of interests

\begin{tabular}{|c|c|c|c|c|c|}
\hline \multirow[b]{2}{*}{ Regions } & \multirow[b]{2}{*}{ Age group } & \multicolumn{3}{|c|}{ Talariach coordinates } & \multirow[b]{2}{*}{ Brodmann area } \\
\hline & & $x$ & $y$ & $z$ & \\
\hline \multirow[t]{3}{*}{ SEF } & Adult & -4 & 3 & 55 & 6 \\
\hline & Teenagers & 0 & 1 & 57 & 6 \\
\hline & Children & 0 & 0 & 58 & 6 \\
\hline \multirow[t]{3}{*}{ R FEF } & Adult & 26 & -6 & 59 & 6 \\
\hline & Teenagers & 27 & -5 & 52 & 6 \\
\hline & Children & 25 & -7 & 58 & 6 \\
\hline \multirow[t]{3}{*}{ LFEF } & Adult & -28 & -9 & 60 & 6 \\
\hline & Teenagers & -28 & -9 & 54 & 6 \\
\hline & Children & -28 & -10 & 57 & 6 \\
\hline \multirow[t]{3}{*}{ R IPreCS } & Adult & 50 & 4 & 35 & 6 \\
\hline & Teenagers & 45 & 2 & 34 & 6 \\
\hline & Children & 45 & 4 & 36 & 6 \\
\hline \multirow[t]{3}{*}{ L IPreCS } & Adult & -38 & 9 & 45 & 6 \\
\hline & Teenagers & -34 & 7 & 41 & 6 \\
\hline & Children & -51 & -1 & 36 & 6 \\
\hline \multirow[t]{3}{*}{ RMFG } & Adult & 39 & 25 & 25 & 9 \\
\hline & Teenagers & 46 & 14 & 30 & 9 \\
\hline & Children & 47 & 20 & 33 & 9 \\
\hline \multirow[t]{3}{*}{ R IFG } & Adult & 56 & 5 & 20 & 44 \\
\hline & Teenagers & 55 & 5 & 17 & 44 \\
\hline & Children & 54 & 3 & 19 & 44 \\
\hline \multirow[t]{3}{*}{ vmPFC } & Adult & 2 & 38 & 5 & 24 \\
\hline & Teenagers & 3 & 34 & 2 & 24 \\
\hline & Children & 11 & 33 & 4 & 24 \\
\hline R Insula & Adult & 36 & 17 & 10 & 13 \\
\hline & Teenagers & 34 & 17 & 8 & 13 \\
\hline & Children & 35 & 17 & 9 & 13 \\
\hline L Insula & Adult & -34 & 14 & 10 & 13 \\
\hline & Teenagers & -33 & 13 & 11 & 13 \\
\hline & Children & -35 & 17 & 6 & 13 \\
\hline RSMG & Adult & 58 & -46 & 22 & 40 \\
\hline & Teenagers & 56 & -45 & 20 & 40 \\
\hline & Children & 54 & -47 & 19 & 40 \\
\hline LSMG & Adult & -57 & -49 & 22 & 40 \\
\hline & Teenagers & -55 & -44 & 18 & 40 \\
\hline & Children & -54 & -46 & 24 & 40 \\
\hline RSPC & Adult & 19 & -69 & 51 & 7 \\
\hline & Teenagers & 20 & -71 & 53 & 7 \\
\hline & Children & 18 & -72 & 52 & 7 \\
\hline LSPC & Adult & -18 & -68 & 52 & 7 \\
\hline & Teenagers & -22 & -67 & 49 & 7 \\
\hline & Children & -17 & -69 & 54 & 7 \\
\hline RIPS & Adult & 26 & -59 & 52 & 7 \\
\hline & Teenagers & 26 & -63 & 55 & 7 \\
\hline & Children & 30 & -59 & 44 & 7 \\
\hline LIPS & Adult & -26 & -63 & 50 & 7 \\
\hline & Teenagers & -29 & -62 & 52 & 7 \\
\hline & Children & -31 & -54 & 47 & 7 \\
\hline R Putamen & Adult & 20 & 3 & 11 & \\
\hline & Teenagers & 21 & 1 & 11 & \\
\hline & Children & 20 & 3 & 15 & \\
\hline L Putamen & Adult & -20 & 1 & 11 & \\
\hline & Teenagers & -21 & 4 & 8 & \\
\hline & Children & -21 & 5 & 15 & \\
\hline R Dorsal medial thalamus & Adult & 10 & -20 & 11 & \\
\hline & Teenagers & 12 & -21 & 15 & \\
\hline & Children & 11 & -20 & 14 & \\
\hline L Dorsal medial thalamus & Adult & -11 & -20 & 10 & \\
\hline & Teenagers & -14 & -20 & 17 & \\
\hline & Children & -13 & -21 & 13 & \\
\hline R Cere & Adult & 32 & -61 & -22 & \\
\hline & Teenagers & 31 & -40 & -31 & \\
\hline & Children & 34 & -57 & -21 & \\
\hline L Cere & Adult & -31 & -59 & -21 & \\
\hline & Teenagers & -31 & -45 & -36 & \\
\hline & Children & -34 & -64 & -25 & \\
\hline
\end{tabular}

Table 1. Continued

\begin{tabular}{llrrrrr}
\hline & & \multicolumn{3}{l}{ Talariach coordinates } & \\
\cline { 3 - 4 } Regions & Age group & $x$ & $y$ & $z$ & \multirow{2}{*}{ Brodmann area } \\
\hline SC & Adult & 5 & -29 & -3 & \\
& Teenagers & 6 & -28 & -4 & \\
\multirow{3}{*}{ R Visual } & Children & 4 & -30 & -6 & \\
& Adult & 11 & -80 & 6 & 17 \\
& Teenagers & 11 & -80 & 1 & 18 \\
L Visual & Children & 11 & -82 & 4 & 17 \\
& Adult & -4 & -86 & 4 & 17 \\
& Teenagers & -6 & -82 & 4 & 17 \\
ACC & Children & -6 & -86 & 4 & 17 \\
& Adult & 7 & 12 & 39 & 32 \\
& Teenagers & 6 & 10 & 44 & 32 \\
& Children & 5 & 12 & 41 & 32
\end{tabular}

L, Left; R, right; Cere, lateral cerebellum, Visual, lingual gyrus/visual cortex.

dures (Efron and Tibshirani, 1994) together with nonparametric tests (Roebroeck et al., 2005). We determined the significance threshold by generating an empirical null distribution of no influence and controlling for multiple comparisons using the false discovery rate (FDR) correction. For each ROI, we segmented its time series into $17.5 \mathrm{~s}$ (11 volumes) mini-blocks and then generated 1000 surrogate time series by shifting the order of the mini-blocks. DOIs obtained from these surrogate time series satisfied the null hypothesis of no influence (DOI of 0 ) because timing was distorted and any influence detected between time series could only be attributable to chance. Time-frequency analyses were performed to verify that this time-shuffling procedure did not affect the overall temporal smoothness of the time series, and the power spectrum between the original time series and surrogate time series were found to be comparable (supplemental Fig. 3, available at www.jneurosci.org as supplemental material).

For each ROI pair, a null distribution was generated by computing the DOI over all surrogate time series and pooling across the median of each age group. The significance level of the DOI of each age group can be determined by measuring the proportion of values in the empirical null distribution that were more extreme than the DOI computed from the real time series (supplemental Fig. 4, available at www.jneurosci.org as supplemental material). Connections that exceeded the threshold of FDR of 0.05 were determined to be significant. Each age group generated two effective connectivity profiles: one for the AS network and one for the PS network. We then contrasted DOIs for the AS network versus the PS network to identify connections associated with inhibitory control processes. For each age group, the significance levels of contrasted DOIs (AS DOI - PS DOI) were also determined using the bootstrap procedure described above, by generating a null distribution of AS DOI - PS DOI $=0$ for each ROI pair and controlling for multiple comparisons with the same threshold (FDR of 0.05).

Group differences were examined for significant connections in which AS $>$ PS. We used Kruskal-Wallis one-way ANOVA tests, with age group as the independent variable and AS DOIs as the dependent measure, correcting for multiple comparisons with the Bonferroni correction. A significant group difference indicated that the strength of effective connectivity was significantly different across age groups. We then performed a Mann-Whitney $U$ test to test for between-group directionality (e.g., adults significantly greater than teenagers, children significantly greater than adults).

Functional connectivity analysis. To provide confirmation of results obtained using GCA, we performed FCA to characterize the development of the functional connectivity network of AS. The preprocessing steps for FCA were the same as GCA, and time series were extracted from the same time window (14th to 79th) for each ROI. The time series from each region was correlated with the time series from every other region, creating a $26 \times 26$ correlation matrix for every subject. Correlation coefficients were Fisher $z$-transformed to improve normality, and connections in which $r>0.2$ were submitted to group analyses examining developmental differences. Developmental changes were tested using an one-way ANOVA, with age group as the independent 
A Adults As
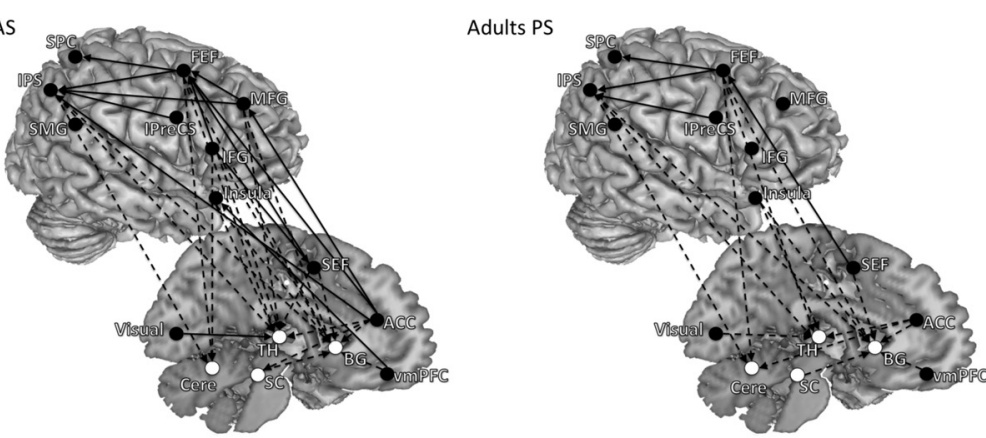

B

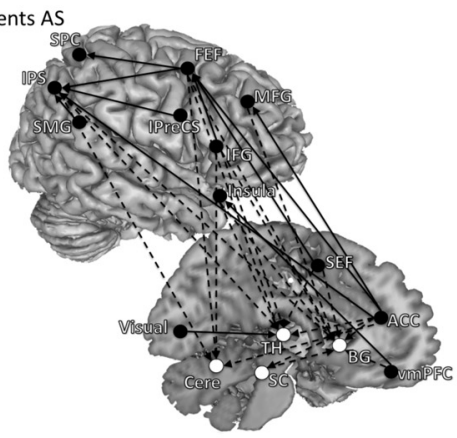

Adolescents PS

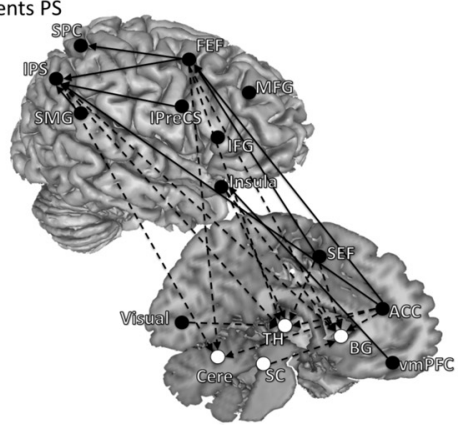

C

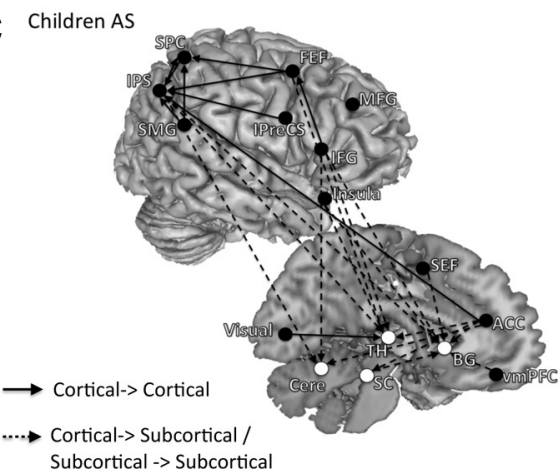

Children PS

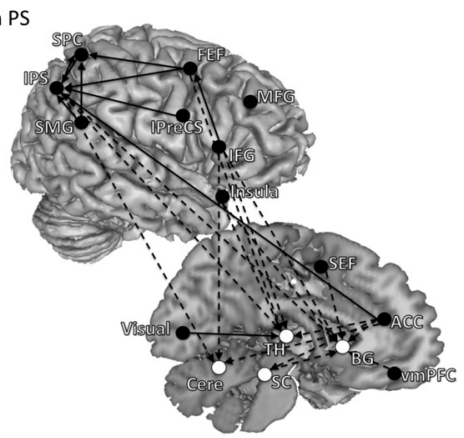

Figure 2. The results of effective connectivity analysis for both the AS and PS tasks, separated by age group and task ( $\boldsymbol{A}$, adults; $\boldsymbol{B}$, adolescents; $\boldsymbol{C}$, children). Both left- and right-hemisphere connections are placed on the right hemisphere to aid with visualization. Arrows connecting two ROIs represent significant effective connectivity from one ROl to another. Only significant connections (FDR $<0.05$ ) are displayed. For the AS task, across age groups we observed dominant influencing connectivity from frontal regions to parietal regions and subcortical regions. Connections were also evident from parietal regions to subcortical regions. The PS connectivity profile lacked connections seen in AS from the right frontal cortex to parietal and subcortical regions.

performed AS trials, which have additional cognitive demands (main effect of condition, $F_{(2,75)}=339.25, p<0.01$; AS mean \pm SD latency: adults, $486 \pm 63 \mathrm{~ms}$; adolescents, $493 \pm 64 \mathrm{~ms}$; children, $539 \pm$ $81 \mathrm{~ms}$; PS mean \pm SD latency: adults, $349 \pm 49 \mathrm{~ms}$; adolescents, $362 \pm 34 \mathrm{~ms}$; children, $395 \pm 45 \mathrm{~ms})$. There was no age group $\times$ condition interaction $\left(F_{(2,75)}=\right.$ $0.254, p>0.77)$. Latencies for correctly performed AS and PS trials were significantly longer for children than for adults and adolescents (AS, $F_{(2,75)}=4.63, p<$ 0.02 ; PS, $\left.F_{(2,75)}=4.18, p<0.02\right)$. There were no latency differences between adolescents and adults, nor between children and adolescents.

\section{Regions of interests}

Twenty-six regions per age group were selected for inclusion in analyses (Table 1, Fig. 1). ROIs included the presupplementary motor area/supplementary eye field (preSMA/SEF), bilateral superior precentral sulcus or the putative human FEF, bilateral inferior precentral sulcus (IPreCS), bilateral intraparietal sulcus (IPS), bilateral superior parietal cortex (SPC), bilateral supramarginal gyrus (SMG), and the visual cortex. ROIs also included several frontal cortex regions, such as the right middle frontal gyrus (MFG), the IFG, bilateral insula, and the ACC. Finally, several subcortical regions were also identified and included bilateral putamen, bilateral dorsal medial thalamus, the superior colliculus (SC), and bilateral superior lateral cerebellum.

\section{Effective connectivity analysis \\ Effective connectivity underlying AS \\ performance}

Across age groups, we observed dominant influence connectivity from frontal re-

variable and $z$-transformed correlation coefficients as the dependent measure, correcting for multiple comparisons with FDR at $q=0.05$. Post hoc $t$ tests were then performed for connections that showed significant group modulations to test for directionality.

\section{Results}

\section{Behavioral results}

Details of behavioral performance were reported by Velanova et al. (2009). The proportion of correctly performed AS trials increased with age (main effect of age group, $F_{(2,75)}=18.51, p<$ 0.0001 ; mean \pm SD accuracy: adults, $0.77 \pm 0.13$; adolescents, $0.66 \pm 0.2$; children, $0.46 \pm 0.22)$ with improvements from childhood to adolescence $\left(t_{(49)}=2.86, p<0.01\right)$ and from adolescence to adulthood $\left(t_{(49)}=2.10, p<0.05\right)$. As expected, correct performance of PS trials was at ceiling (accuracy across age groups $>0.98, \mathrm{SD}<0.02)$ and did not differ between age groups (main effect of age group, $F_{(2,75)}=1.04, p>0.35$ ).

Not surprisingly, across age groups correctly performed PS trials had latencies that were significantly shorter than correctly gions, including the ACC, the right MFG, the right IFG, bilateral insula, the SEF and bilateral FEF to cortical parietal regions (bilateral IPS, bilateral SPC), the visual cortex, and subcortical regions (bilateral putamen, bilateral dorsal medial thalamus, SC and bilateral cerebellum) (Fig. 2, Table 2). Connections were also evident from cortical parietal regions to subcortical regions, visual cortex to thalamus, and SC to the basal ganglia. The median DOI of each connection and its significance level derived from the bootstrapping procedure are presented in supplemental Tables 1-3 (available at www.jneurosci.org as supplemental material).

\section{Effective connectivity underlying PS performance}

Across age groups, PS activity generated a similar effective connectivity pattern to AS activity and included a range of corticalcortical and cortical-subcortical connections (Fig. 2, Table 2). The notable difference is that the PS connectivity profile lacked connections seen in AS from the right frontal cortex (the right 
Table 2. List of significant connections for each age group and condition

\begin{tabular}{|c|c|c|c|c|c|c|c|}
\hline \multirow[b]{2}{*}{ Source ROI } & \multirow[b]{2}{*}{ Target ROI } & \multicolumn{2}{|c|}{ Adults } & \multicolumn{2}{|c|}{ Adolescents } & \multicolumn{2}{|c|}{ Children } \\
\hline & & AS & PS & AS & PS & AS & PS \\
\hline preSMA/SEF & RFEF & $x$ & $x$ & $x$ & $x$ & - & - \\
\hline preSMA/SEF & R Thalamus & $x$ & - & $x$ & $x$ & - & - \\
\hline preSMA/SEF & L Putamen & $x$ & $x$ & $x$ & $x$ & $x$ & - \\
\hline RFEF & RIPS & $x$ & $x$ & $x$ & $x$ & $x$ & $x$ \\
\hline RFEF & L Putamen & $x$ & $x$ & $\mathrm{x}$ & $x$ & - & - \\
\hline RFEF & R Thalamus & $x$ & $x$ & - & - & - & - \\
\hline RFEF & R Cerebellum & $x$ & $x$ & $x$ & $x$ & - & - \\
\hline LFEF & LIPS & $x$ & $x$ & $x$ & $x$ & - & - \\
\hline LFEF & RSPC & $x$ & $x$ & $x$ & $x$ & $x$ & $x$ \\
\hline LFEF & L Putamen & $x$ & $x$ & - & - & - & - \\
\hline LFEF & L Thalamus & $x$ & - & $x$ & $x$ & - & - \\
\hline LFEF & R Thalamus & - & - & $x$ & $x$ & $x$ & - \\
\hline RIPreCS & RIPS & $x$ & - & $x$ & $x$ & - & - \\
\hline R IPreCS & LIPS & $x$ & $x$ & $x$ & - & $x$ & $x$ \\
\hline L IPreCS & LIPS & $x$ & $x$ & $x$ & $x$ & - & - \\
\hline LIPreCS & RIPS & - & - & - & - & $x$ & $\mathrm{x}$ \\
\hline R MFG & RFEF & $x$ & - & - & - & - & - \\
\hline R MFG & LFEF & $x$ & - & - & - & - & - \\
\hline R MFG & LIPS & $x$ & - & - & - & - & - \\
\hline R MFG & R Putamen & $x$ & - & $x$ & - & - & - \\
\hline R MFG & R Thalamus & $x$ & - & - & - & - & - \\
\hline RIFG & preSMA/SEF & $x$ & - & - & - & - & - \\
\hline RIFG & RFEF & $x$ & - & $x$ & - & $x$ & - \\
\hline RIFG & LFEF & $x$ & - & - & - & - & - \\
\hline RIFG & L Putamen & $x$ & - & $x$ & - & $x$ & - \\
\hline RIFG & R Thalamus & $x$ & - & $x$ & - & $x$ & - \\
\hline RIFG & $\mathrm{R}$ Cerebellum & $x$ & - & $x$ & - & $x$ & - \\
\hline RIFG & L Cerebellum & $x$ & - & $x$ & - & - & - \\
\hline vmPFC & R Putamen & $x$ & $x$ & $x$ & - & $x$ & - \\
\hline vmPFC & R Insula & $x$ & - & $x$ & $x$ & - & - \\
\hline vmPFC & L Putamen & - & $x$ & - & - & - & - \\
\hline R Insula & L Putamen & $x$ & $x$ & $x$ & $x$ & - & - \\
\hline R Insula & R Thalamus & $x$ & $x$ & - & - & - & - \\
\hline L Insula & L Putamen & $x$ & $x$ & $x$ & $x$ & - & - \\
\hline L Insula & L Thalamus & $x$ & $x$ & $x$ & $x$ & - & - \\
\hline RIPS & R Putamen & $x$ & $x$ & $x$ & $x$ & $x$ & - \\
\hline RIPS & R Cerebellum & $x$ & $x$ & $x$ & $x$ & $x$ & - \\
\hline LIPS & R Thalamus & $x$ & $x$ & $x$ & $x$ & $x$ & - \\
\hline LIPS & R Cerebellum & $x$ & $x$ & $x$ & $x$ & $x$ & - \\
\hline RIPS & LSPC & - & - & - & - & $x$ & - \\
\hline RIPS & LIPS & - & - & - & - & $x$ & - \\
\hline RSPC & RIPS & - & - & - & - & $x$ & $x$ \\
\hline LSPC & LIPS & - & - & - & - & $x$ & $x$ \\
\hline RSMG & RIPS & - & - & $\mathrm{x}$ & $x$ & $x$ & $x$ \\
\hline RSMG & R SPC & - & - & - & - & $x$ & - \\
\hline LSMG & LIPS & - & - & $x$ & - & $x$ & - \\
\hline LSMG & LSPC & - & - & - & - & $x$ & $x$ \\
\hline SC & R Putamen & $x$ & $x$ & $x$ & $x$ & $x$ & $x$ \\
\hline R Visual & R Thalamus & $x$ & $x$ & $x$ & $x$ & $x$ & $x$ \\
\hline R Visual & L Thalamus & $x$ & $x$ & $x$ & $x$ & $x$ & $x$ \\
\hline L Visual & L Thalamus & - & $x$ & - & - & - & $x$ \\
\hline $\mathrm{ACC}$ & RFEF & $x$ & - & $x$ & $\mathrm{x}$ & - & - \\
\hline $\mathrm{ACC}$ & R MFG & $x$ & - & $x$ & - & - & - \\
\hline ACC & RIPS & $x$ & - & $x$ & $x$ & $x$ & $x$ \\
\hline $\mathrm{ACC}$ & LIPS & $x$ & - & $x$ & $x$ & $x$ & $x$ \\
\hline $\mathrm{ACC}$ & R Putamen & $x$ & $x$ & $x$ & $x$ & $x$ & - \\
\hline $\mathrm{ACC}$ & R Thalamus & $x$ & $x$ & $x$ & - & $x$ & - \\
\hline $\mathrm{ACC}$ & L Thalamus & $x$ & $x$ & $x$ & $x$ & $x$ & - \\
\hline $\mathrm{ACC}$ & R Cerebellum & $x$ & $x$ & $x$ & $x$ & $x$ & - \\
\hline $\mathrm{ACC}$ & L Cerebellum & $x$ & $x$ & - & - & - & - \\
\hline
\end{tabular}

L, Left; R, right; Visual, lingual gyrus/visual cortex; $x$, significant connection; - , no significant connection.

MFG, the right IFG). The median DOI of each connection and its significance level derived from the bootstrapping procedure are presented in supplemental Tables 4-6 (available at www. jneurosci.org as supplemental material).
Adults AS>PS
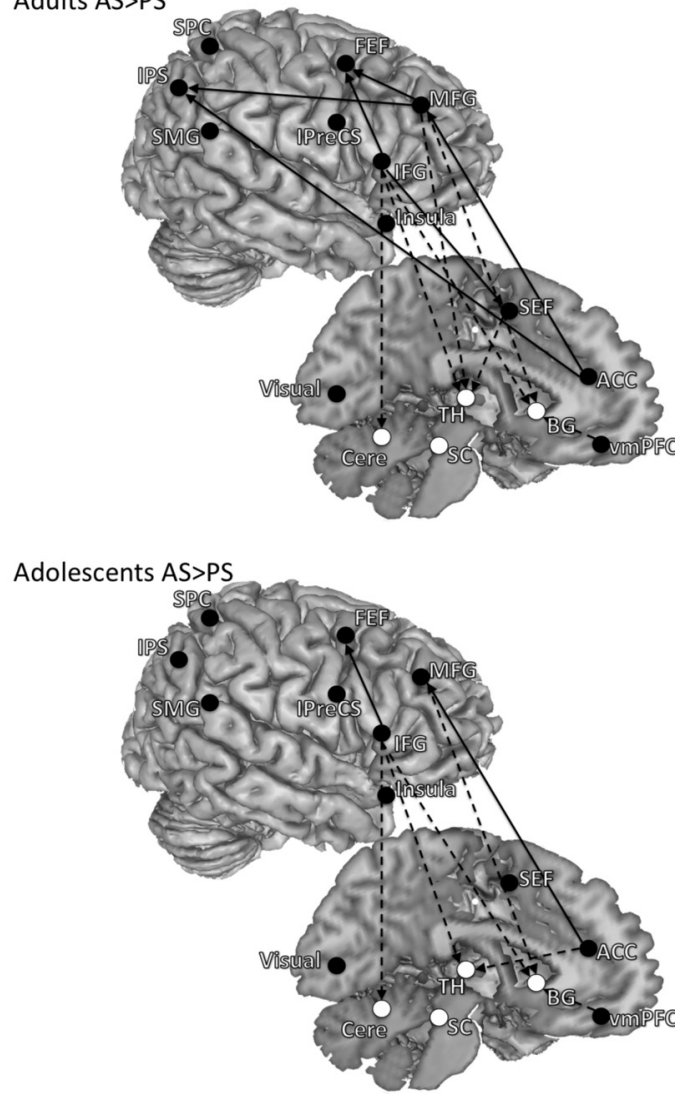

Children AS>PS

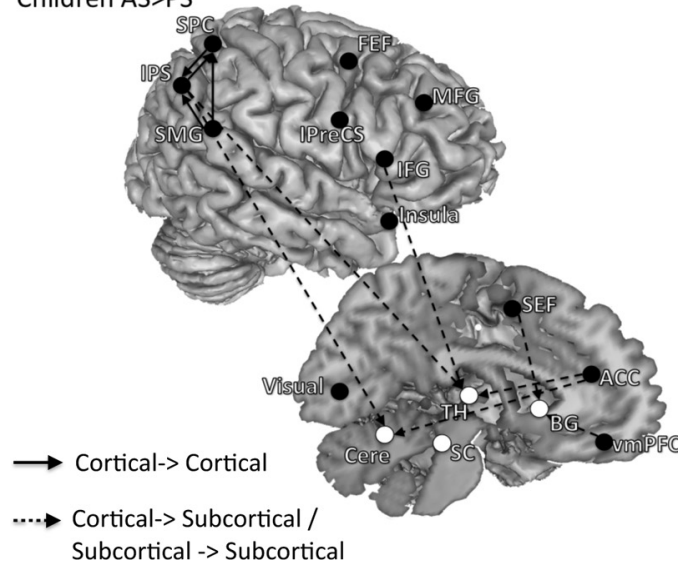

Figure 3. The results of contrasting effective connectivity between task conditions separated by age group. Both left- and right-hemisphere connections are placed on the right hemisphere to aid with visualization. These are connections in which effective connectivity strengths were significantly greater or more asymmetric for AS compared with PS (FDR $<0.05$ ). These connections are likely involved in active inhibitory control processes. For all age groups, no connections showed greater effective connectivity strength for PS compared with AS.

\section{AS versus $P S$}

Compared with the AS network, the PS network lacked dominant influencing connections from the right lateral prefrontal cortex and showed fewer connections. For adults and adolescents, influencing connections from the right lateral frontal cortex (the right MFG, the right IFG) to parietal and/or subcortical regions were significantly stronger or more asymmetric in the AS network compared with the PS network, whereas for children, effective connectivity within the parietal cortex was stronger or more asymmetric (Fig. 3, Table 3 ). The AS compared with PS network also showed stronger or more asymmetric connections from the ACC to parietal and sub- 
Table 3. List of significant connections in which AS > PS

\begin{tabular}{|c|c|c|c|c|}
\hline Source ROI & Target ROI & Adults & Adolescents & Children \\
\hline preSMA/SEF & R Thalamus & $x$ & - & - \\
\hline preSMA/SEF & L Putamen & - & - & $x$ \\
\hline R MFG & RFEF & $x$ & - & - \\
\hline R MFG & LFEF & $x$ & - & - \\
\hline R MFG & LIPS & $x$ & - & - \\
\hline R MFG & R Putamen & $x$ & $x$ & - \\
\hline R MFG & R Thalamus & $x$ & - & - \\
\hline RIFG & preSMA/SEF & $\mathrm{x}$ & - & - \\
\hline RIFG & RFEF & $\mathrm{x}$ & $x$ & - \\
\hline RIFG & LFEF & $x$ & - & - \\
\hline RIFG & L Putamen & $\mathrm{x}$ & $x$ & - \\
\hline RIFG & R Thalamus & $\mathrm{x}$ & $\mathrm{x}$ & $\mathrm{x}$ \\
\hline RIFG & R Cerebellum & $x$ & $x$ & - \\
\hline RIFG & LCerebellum & $x$ & $x$ & - \\
\hline RIPS & R Cerebellum & - & - & $x$ \\
\hline RIPS & LSPC & - & - & $x$ \\
\hline LIPS & R Thalamus & - & - & $x$ \\
\hline LSPC & LIPS & - & - & $\mathrm{x}$ \\
\hline RSMG & RSPC & - & - & $x$ \\
\hline LSMG & LIPS & - & - & $x$ \\
\hline $\mathrm{ACC}$ & RIPS & $\mathrm{x}$ & - & - \\
\hline $\mathrm{ACC}$ & LIPS & $x$ & - & - \\
\hline $\mathrm{ACC}$ & R MFG & $\mathrm{x}$ & $\mathrm{x}$ & - \\
\hline $\mathrm{ACC}$ & R Thalamus & - & $\mathrm{x}$ & $\mathrm{x}$ \\
\hline $\mathrm{ACC}$ & L Thalamus & - & - & $x$ \\
\hline $\mathrm{ACC}$ & $\mathrm{R}$ Cerebellum & - & - & $\mathrm{x}$ \\
\hline
\end{tabular}

L, Left; R, right; $x$, significant connection; - , no significant connection.
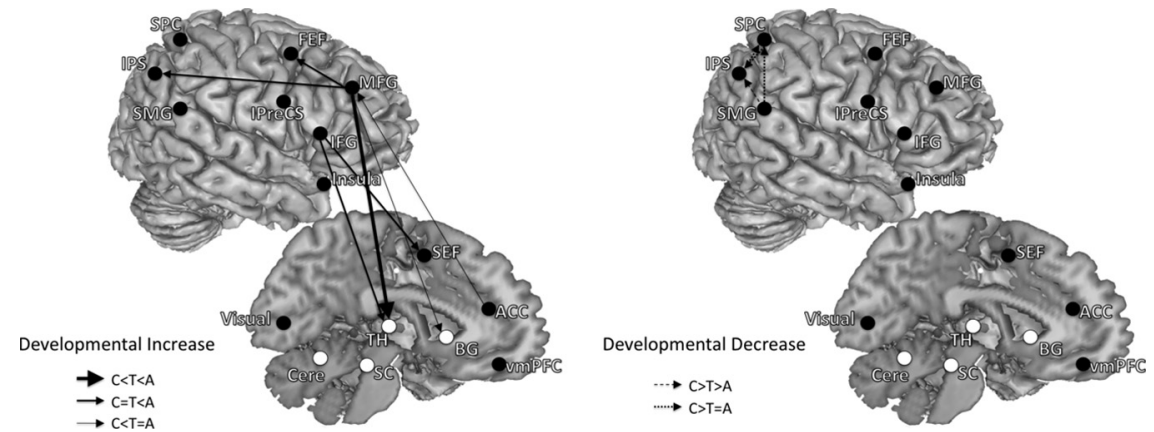

Figure 4. Developmental patterns of effective connectivity underlying inhibitory control. These are connections in which effective connectivity strengths were significantly different across age groups (children, adolescents, adults). Both left- and right-hemisphere connections are placed on the right hemisphere to aid with visualization. Connections are grouped into two overarching developmental patterns: developmental increase and developmental decrease. Left shows connections that showed developmental increase in effective connectivity strengths (adults significantly greater than adolescents and/or adolescents significantly greater than children). Right shows connections that showed developmental decrease in effective connectivity strengths (children significantly greater than adolescents and/or adolescents significantly greater than adults). Solid lines with arrows represent developmental increasing connections, and dashed lines with arrows represent developmental decreasing connections. Connections from frontal to parietal and subcortical regions increased with age, whereas connections within the parietal cortex decreased with age. A, Adults; C, children; T, adolescents.

cortical regions. For all age groups, no connections showed stronger or more asymmetric connectivity strengths in the PS network compared with the AS network. The median of the contrasted DOI (AS - PS) of each connection and its significant level derived from the bootstrapping procedure are presented in supplemental Tables 7-9 (available at www.jneurosci.org as supplemental material).

Developmental changes of effective connectivity

Developmental patterns of connections that were greater for the AS network compared with the PS network showed two key developmental differences: (1) compared with adults and adolescents, children showed stronger short-range connections within

\section{Discussion}

the parietal cortex, and (2) influencing connections from frontal regions to other regions increased with age. We summarize the developmental changes of effective connectivity in Figures 4 and 5 , dividing connections into two overarching developmental patterns: developmental increases and developmental decreases.

\section{Developmental increases}

From childhood to adolescence, effective connectivity increased in the following pathways: SEF to the thalamus, ACC to the right MFG, the right MFG to the putamen and the right thalamus. During the transition from adolescence to adulthood, the strength of effective connectivity from frontal regions (ACC, right MFG, right IFG, FEF, IPreCS) to multiple downstream sensorimotor regions, including the IPS and subcortical regions (thalamus and cerebellum), increased with age.

\section{Developmental decreases}

In contrast, short-range connectivity strengths within the parietal cortex decreased with age. Effective connectivity from SMG to the IPS decreased with age from childhood to adolescence and adulthood. Connections between the right SMG and the right SPC, the right IPS and the left SPC, the left SPC and the left IPS decreased with age from childhood to adolescence. Developmental decreases in effective connectivity within the parietal cortex appear mostly complete by adolescence, because from adolescence into adulthood fewer decreasing connectivity changes were found.

\section{Functional connectivity analysis}

Developmental changes in functional connectivity underlying inhibitory control primarily paralleled our effective connectivity results. We found that short-range connections within the frontal and the parietal cortex decreased in strength with age for the AS task (Fig. 6). Within the frontal cortex, we found decreases in functional connectivity between right MFG and the right insula, the ventromedial prefrontal cortex (vmPFC) and the right IFG, the right IFG and left insula, the left FEF and left IPreCS, the right MFG and bilateral IPreCS, and the ACC and the right IFG with age. Within the parietal cortex, similar to our effective connectivity results, we found decreases in functional connectivity between bilateral SMG and the right IPS, and the right IPS and bilateral SPC. Most of these short-range decreases were complete by adolescence, whereas a few connections within the frontal cortex showed continuing decreases into adulthood (e.g., ACC-right IFG and right MFG-right insula). Similar to our effective connectivity results, long-range functional connectivity between distant ROIs also showed increases with age. We found increases in functional connectivity strengths between right IFG and the left IPS, the right IFG and the right SPC, bilateral SMG and the right putamen, the right SMG and SC, the left SMG and the right cerebellum, the left insula and the right putamen, and the ACC and the right IFG.

The overall goal of our study was to characterize the development of inter-regional interactions that support active inhibitory con- 
trol. Our results suggest that adults' mature inhibitory control was supported by exerting top-down cognitive control from multiple frontal regions to downstream cortical and subcortical regions associated with oculomotor processing (Müri et al., 1998; Munoz and Everling, 2004; Everling and Desouza, 2005; Pierrot-Deseilligny et al., 2005; Bressler et al., 2008; Duann et al., 2009). Developmentally, our results indicate that developmental improvements in inhibitory control are supported by enhanced in top-down connectivity from frontal cognitive control regions to downstream effector regions and decreases in short-range connectivity within parietal and frontal regions.

\section{Mature inhibitory control is supported by the integration of multiple distributed cortical regions through top-down connectivity}

To identify connections that were associated with active inhibitory control processes, we examined connections in which effective connectivity strengths were significantly greater or more asymmetric for the AS compared with the PS condition. Our results suggest that establishing top-down connectivity from frontal cortical regions to cortical and subcortical oculomotor regions supports inhibitory control. These top-down connections originated from the ACC, the right MFG, and right IFG. The right MFG has been implicated to be involved in attentional control (Corbetta and Shulman, 2002), task-rule representation (Crone et al., 2006), task-set maintenance (Sakai, 2008), and working memory processes (Curtis and D'Esposito, 2003). Effective connectivity from the right MFG to the basal ganglia and FEF may assist with the programming of eye-movement output and connections to the thalamus that have been found to support the generation of antisaccades (Kunimatsu and Tanaka, 2010). The right IFG is associated with cognitive inhibition (Konishi et al., 1998; Aron et al., 2003, 2004; Duann et al., 2009). Connectivity from the right IFG may contribute to inhibition of the prepotent PS output that is being prepared in the SEF, the FEF, the putamen, and the cerebellum. The ACC has consistently been found to support performance monitoring (Paus et al., 1993; Rushworth et al., 2004; Velanova et al., 2008) and to signal error (Schall and Boucher, 2007) or conflict (Carter et al., 1998; Kerns et al., 2004; Cavanagh et al., 2009). We found connections from ACC to oculomotor regions (IPS and FEF) and to the right MFG. Compared with the PS task, the AS task created more conflict in response preparation and induced more behavioral error (as evident in our behavioral results). ACC may enhance cognitive control functions through the right MFG (Cavanagh et al., 2009) and assist in preparing oculomotor regions for making the correct motor output. Compared with the AS task, the PS task lacked these dominant influencing top-down connections from the
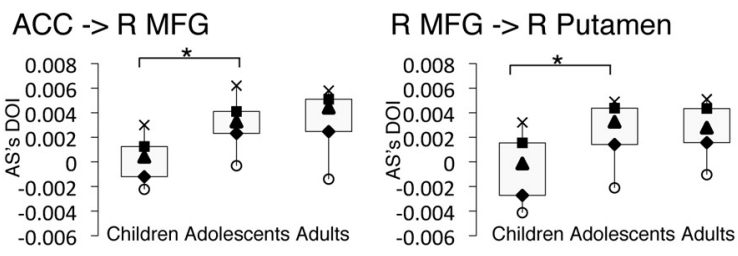

R MFG -> L IPS

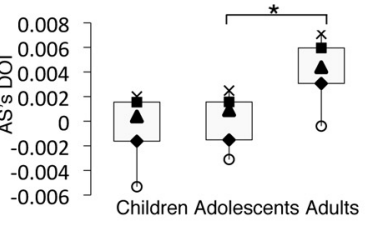

R IFG -> SEF
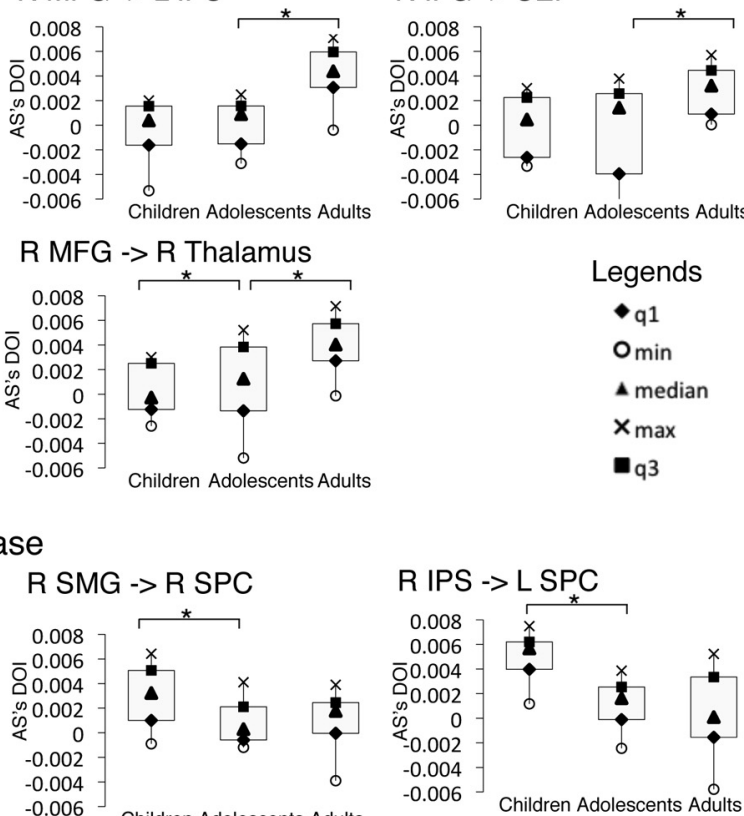

Figure 5. Box plots of developmental changes in effective connectivity. These are connections in which effective connectivity mental increase in effective connectivity strengths (adults significantly greater than adolescents and/or adolescents significantly greater than children). $\boldsymbol{B}$ shows connections that showed developmental decrease in effective connectivity strengths (children significantly greater than adolescents and/or adolescents significantly greater than adults). L, Left; $R$, right.

frontal cortex, which could reflect its relatively lighter cognitive demand.

Several significant connections were found when examining the AS and PS effective connectivity networks separately, and these were found to be equivalent across the AS and PS conditions. These connections extended from visual cortex to the thalamus, and the SC to basal ganglia. These connections may reflect basic sensory-relay functions from the visual cortex to the thalamus (Kawamura et al., 1974; Guillery and Sherman, 2002; Cappe et al., 2009) and reflect saccade programming coordination between the basal ganglia and the SC (Munoz and Everling, 2004). We also found several connections within the oculomotor circuitry in both the AS and PS conditions, such as FEF to IPS and IPreCS to IPS. These connections are likely involved in coordinating oculomotor functions for executing eye movement outputs (Miller et al., 2005; Pierrot-Deseilligny et al., 2005; Brown et al., 2007).

Multiple top-down connections act in concert to support inhibitory control. Our results suggest that there is no single ana- 

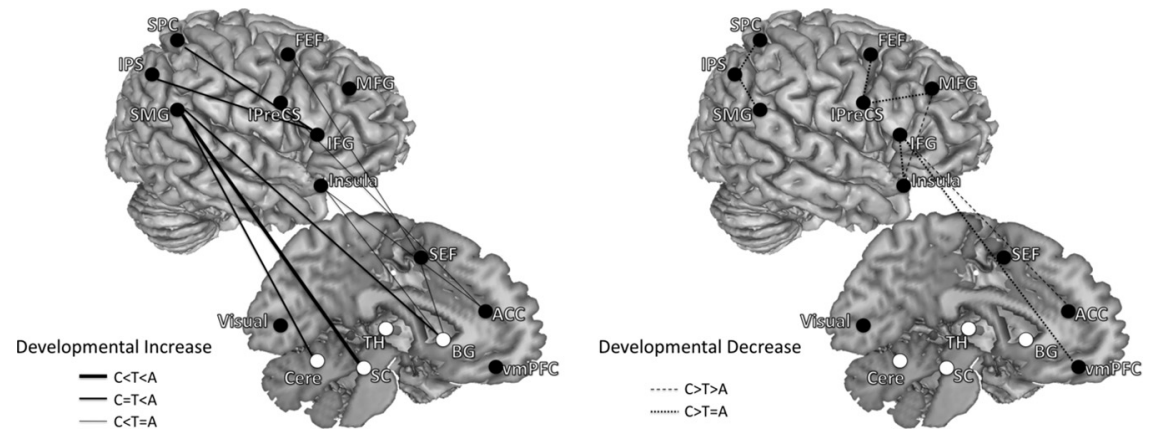

Figure 6. Developmental patterns of functional connectivity associated with the AS task. Connections are grouped into two overarching developmental patterns: developmental increase and developmental decrease. Both left- and right-hemisphere connections are placed on the right hemisphere to aid with visualization. Left shows connections that showed developmental increases in functional connectivity (adults significantly greater than adolescents and/or adolescents significantly greater than children). Right shows connections that showed developmental decreases in functional connectivity (children significantly greater than adolescents and/or adolescents significantly greater than adults). Solid lines represent developmental increasing connections, and dashed lines represent developmental decreasing connections. Functional connectivity between distant regions increased with age, whereas functional connectivity within the frontal and parietal cortex decreased with age. A, Adults; $C$, children; $\mathrm{T}$, adolescents.

tomical region that is the locus of inhibitory control functions. Instead, active inhibitory control is accomplished by collaborating oculomotor function, task goal maintenance, attentional control, and response inhibition across a distributed circuitry.

\section{Developmental improvements in inhibitory control are supported by enhancing top-down connectivity from the frontal cortex}

The mature (adult-level) inhibitory control circuitry was characterized by strong top-down connectivity between the frontal cortex and parietal and subcortical regions, but developing populations showed a qualitatively different connectivity pattern. Children did not show top-down connectivity from the right MFG and had fewer and weaker connections from the right IFG. When examining the AS and PS networks separately, children showed effective connectivity between key oculomotor regions such as the FEF and IPS, suggesting that basic oculomotor function is established by childhood. However, for inhibitory control (i.e., AS > PS connections), children's effective connectivity profile was dominated by strong short-range connectivity within the parietal cortex. This could be attributable to children's relatively weaker communication between the cognitive resources of the frontal cortex and downstream sensorimotor functions, prompting reliance on visuospatial attention strategies that are coordinated in the parietal cortex. These results are similar to our previous study that also found a robust recruitment of parietal regions in childhood (Luna et al., 2001). For adolescents, topdown connections from the right IFG that were already established in childhood continued to increase their connectivity strength with age. Furthermore, several new top-down connections from the right MFG and ACC emerged. The strong withinparietal connectivity pattern weakened from childhood to adolescence and was absent by adulthood. These results suggest that adolescents had stronger connectivity that enabled frontal cortex to exert cognitive control over downstream oculomotor regions. However, when compared with adults, adolescents' topdown connectivity was still not adult-like. Preexisting top-down connectivity from right IFG to the thalamus and ACC to the right MFG continued to strengthen from adolescence to adulthood. New connections from right MFG to the thalamus and the FEF emerged in adulthood. Together, these results suggest that, during adolescence, there is continued strengthening of top-down influence from frontal to downstream effector regions.

Results from the developmental profile of effective connectivity associated with active inhibitory control (i.e., AS > PS) revealed two overarching patterns (Figs. 4, 5). First, top-down connectivity from the frontal cortex strengthened with age. In particular, top-down connections that support cognitive control continued to develop from childhood to adolescence and into adulthood, whereas basic oculomotor connectivity was adult-like by adolescence. Second, short-range connections that are close in anatomical space decreased with age. Results showed strong connectivity within the parietal cortex in children that was greatly reduced by adolescence and no longer seen in adults. A parallel pattern was also found in our FCA results (Fig. 6), which showed that shortrange connections within frontal and parietal cortex weakened from childhood to adulthood.

Overall, our developmental results are consistent with previous rs-fcMRI reports (Fair et al., 2007) indicating that connectivity strength between distant regions increases with age, whereas regions close in proximity gradually segregate from each other (Fair et al., 2009). Additionally, we found that the development of top-down effective connectivity from cognitive control regions is critical in supporting active inhibitory control. This result is also consistent with previous reports that developmental changes in effective connectivity are associated with age-related improvements in cognitive processes (Bitan et al., 2006, 2009; Stevens et al., 2007). Critically, we found that changes in both the strength and the number of connections underlie developmental improvements in inhibitory control. Interestingly, developmental increases in top-down connectivity are in contrast to visual perceptual learning studies showing that with training the reverse is evident (Lewis et al., 2009), underscoring that the nature of developmental improvements in response inhibition are supported by establishing top-down connectivity for cognitive control. Together, these results support our proposal that what characterizes the transition from adolescence to adulthood is engagement of more distributed networks that act in a collaborative manner to support top-down executive control of behavior (Luna and Sweeney, 2004). The antisaccade task is also associated with a wide range of cognitive control processes beyond inhibitory control. The developmental changes we found in cortical-subcortical pathways could potentially be involved in a broader realm of executive control functions such as error-related cognitive control and behavioral adjustment (Ide and Li, 2010).

Developmental enhancements in top-down connectivity are likely supported by the maturation of white matter tracts connecting distributed cortical regions. Brain maturation processes, including myelination and synaptic pruning, support white matter integrity (Yakovlev et al., 1967; Huttenlocher, 1979), and both enhance neuronal communication. Our results are in accord with our recent findings that the integrity of association and projection white matter tracts that provide connections between frontal, subcortical, and parietal regions are still immature in adolescence (Asato et al., 2010). Functionally, increased white matter integrity would support better synchronization of neural 
signals across a distributed cortical circuitry (Olesen et al., 2003; Boorman et al., 2007; Stufflebeam et al., 2008).

\section{Conclusions}

Our results suggest that, in addition to known immaturities in localized function, top-down connectivity from the frontal cortex also continues to mature into adulthood. Developmental improvements in inhibitory control thus may be supported by both the maturation of localized brain function and enhancement in coordinating cognitive control functions through top-down connectivity between frontal, oculomotor, and subcortical regions. Immaturities in the development of effective connectivity could provide important insights into the emergence of psychopathology and risk-taking behaviors in adolescents.

\section{References}

Aron AR, Fletcher PC, Bullmore ET, Sahakian BJ, Robbins TW (2003) Stopsignal inhibition disrupted by damage to right inferior frontal gyrus in humans. Nat Neurosci 6:115-116.

Aron AR, Robbins TW, Poldrack RA (2004) Inhibition and the right inferior frontal cortex. Trends Cogn Sci 8:170-177.

Asato MR, Terwilliger R, Woo J, Luna B (2010) White matter development in adolescence: a DTI study. Cereb Cortex 20:2122-2131.

Berman RA, Colby CL, Genovese CR, Voyvodic JT, Luna B, Thulborn KR, Sweeney JA (1999) Cortical networks subserving pursuit and saccadic eye movements in humans: an fMRI study. Hum Brain Mapp 8:209-225.

Bitan T, Burman DD, Lu D, Cone NE, Gitelman DR, Mesulam MM, Booth JR (2006) Weaker top-down modulation from the left inferior frontal gyrus in children. Neuroimage 33:991-998.

Bitan T, Cheon J, Lu D, Burman DD, Booth JR (2009) Developmental increase in top-down and bottom-up processing in a phonological task: an effective connectivity, fMRI study. J Cogn Neurosci 21:1135-1145.

Boorman ED, O'Shea J, Sebastian C, Rushworth MF, Johansen-Berg H (2007) Individual differences in white-matter microstructure reflect variation in functional connectivity during choice. Curr Biol 17:1426-1431.

Braver TS, Barch DM, Gray JR, Molfese DL, Snyder A (2001) Anterior cingulate cortex and response conflict: effects of frequency, inhibition and errors. Cereb Cortex 11:825-836.

Bressler SL, Seth AK (2010) Wiener-Granger Causality: A well established methodology. Neuroimage. Advance online publication. Retrieved October 5, 2010. doi:10.1016/j.neuroimage.2010.02.059.

Bressler SL, Tang W, Sylvester CM, Shulman GL, Corbetta M (2008) Topdown control of human visual cortex by frontal and parietal cortex in anticipatory visual spatial attention. J Neurosci 28:10056-10061.

Brown MR, Vilis T, Everling S (2007) Frontoparietal activation with preparation for antisaccades. J Neurophysiol 98:1751-1762.

Bunge SA, Dudukovic NM, Thomason ME, Vaidya CJ, Gabrieli JD (2002) Immature frontal lobe contributions to cognitive control in children: evidence from fMRI. Neuron 33:301-311.

Buschman TJ, Miller EK (2007) Top-down versus bottom-up control of attention in the prefrontal and posterior parietal cortices. Science 315:1860-1862.

Cappe C, Morel A, Barone P, Rouiller EM (2009) The thalamocortical projection systems in primate: an anatomical support for multisensory and sensorimotor interplay. Cereb Cortex 19:2025-2037.

Carter CS, Braver TS, Barch DM, Botvinick MM, Noll D, Cohen JD (1998) Anterior cingulate cortex, error detection, and the online monitoring of performance. Science 280:747-749.

Casey BJ, Trainor RJ, Orendi JL, Schubert AB, Lystrom LE, Giedd JN, Castellanos FX, Haxby JV, Noll DC, Cohen JD, Forman SD, Dahl RE, Rapoport JL (1997) A developmental functional MRI study of prefrontal activation during performance of a go-no-go task. J Cogn Neurosci 9:835-847.

Cavanagh JF, Cohen MX, Allen JJ (2009) Prelude to and resolution of an error: EEG phase synchrony reveals cognitive control dynamics during action monitoring. J Neurosci 29:98-105.

Chang C, Thomason ME, Glover GH (2008) Mapping and correction of vascular hemodynamic latency in the BOLD signal. Neuroimage 43:90-102.

Clementz BA, Brahmbhatt SB, McDowell JE, Brown R, Sweeney JA (2007)
When does the brain inform the eyes whether and where to move? An EEG study in humans. Cereb Cortex 17:2634-2643.

Corbetta M, Shulman GL (2002) Control of goal-directed and stimulusdriven attention in the brain. Nat Rev Neurosci 3:201-215.

Crone EA, Donohue SE, Honomichl R, Wendelken C, Bunge SA (2006) Brain regions mediating flexible rule use during development. J Neurosci 26:11239-11247.

Curtis CE, D'Esposito M (2003) Persistent activity in the prefrontal cortex during working memory. Trends Cogn Sci 7:415-423.

Curtis CE, Cole MW, Rao VY, D’Esposito M (2005) Canceling planned action: an FMRI study of countermanding saccades. Cereb Cortex 15:12811289.

David O, Guillemain I, Saillet S, Reyt S, Deransart C, Segebarth C, Depaulis A (2008) Identifying neural drivers with functional MRI: an electrophysiological validation. PLoS Biol 6:2683-2697.

de Pasquale F, Della Penna S, Snyder AZ, Lewis C, Mantini D, Marzetti L, Belardinelli P, Ciancetta L, Pizzella V, Romani GL, Corbetta M (2010) Temporal dynamics of spontaneous MEG activity in brain networks. Proc Natl Acad Sci U S A 107:6040-6045.

Deshpande G, Sathian K, Hu X (2010) Effect of hemodynamic variability on Granger causality analysis of fMRI. Neuroimage 52:884-896.

Diamond A (1989) Developmental progression in human infants and infant monkeys, and the neural bases of, inhibitory control of reaching. In: The development and neural bases of higher cognitive functions. New York: Academy of Science.

Diamond A, Goldman-Rakic PS (1989) Comparison of human infants and rhesus monkeys on Piaget's AB task: evidence for dependence on dorsolateral prefrontal cortex. Exp Brain Res 74:24-40.

Ding M, Bressler SL, Yang W, Liang H (2000) Short-window spectral analysis of cortical event-related potentials by adaptive multivariate autoregressive modeling: data preprocessing, model validation, and variability assessment. Biol Cybern 83:35-45.

Dosenbach NU, Visscher KM, Palmer ED, Miezin FM, Wenger KK, Kang HC, Burgund ED, Grimes AL, Schlaggar BL, Petersen SE (2006) A core system for the implementation of task sets. Neuron 50:799-812.

Dosenbach NU, Fair DA, Miezin FM, Cohen AL, Wenger KK, Dosenbach RA, Fox MD, Snyder AZ, Vincent JL, Raichle ME, Schlaggar BL, Petersen SE (2007) Distinct brain networks for adaptive and stable task control in humans. Proc Natl Acad Sci U S A 104:11073-11078.

Duann JR, Ide JS, Luo X, Li CS (2009) Functional connectivity delineates distinct roles of the inferior frontal cortex and presupplementary motor area in stop signal inhibition. J Neurosci 29:10171-10179.

Durston S, Thomas KM, Yang YH, Ulug AM, Zimmerman RD, Casey BJ (2002) A neural basis for the development of inhibitory control. Dev Sci 5:F9-F16.

Efron B, Tibshirani R (1994) Introduction to the bootstrap. Monographs on statistics and applied probability. New York: Chapman and Hall.

Everling S, DeSouza JF (2005) Rule-dependent activity for prosaccades and antisaccades in the primate prefrontal cortex. J Cogn Neurosci 17:1483-1496.

Fair DA, Dosenbach NU, Church JA, Cohen AL, Brahmbhatt S, Miezin FM, Barch DM, Raichle ME, Petersen SE, Schlaggar BL (2007) Development of distinct control networks through segregation and integration. Proc Natl Acad Sci U S A 104:13507-13512.

Fair DA, Cohen AL, Power JD, Dosenbach NU, Church JA, Miezin FM, Schlaggar BL, Petersen SE (2009) Functional brain networks develop from a "local to distributed" organization. PLoS Comput Biol 5:e1000381.

Fischl B, Salat DH, Busa E, Albert M, Dieterich M, Haselgrove C, van der Kouwe A, Killiany R, Kennedy D, Klaveness S, Montillo A, Makris N, Rosen B, Dale AM (2002) Whole brain segmentation: automated labeling of neuroanatomical structures in the human brain. Neuron 33:341-355.

Ford KA, Everling S (2009) Neural activity in primate caudate nucleus associated with pro- and antisaccades. J Neurophysiol 102:2334-2341.

Friston KJ, Holmes AP, Poline JB, Grasby PJ, Williams SC, Frackowiak RS, Turner R (1995) Analysis of fMRI time-series revisited. Neuroimage 2:45-53.

Friston KJ, Harrison L, Penny W (2003) Dynamic causal modelling. Neuroimage 19:1273-1302.

Gitelman DR (2002) ILAB: a program for postexperimental eye movement analysis. Behav Res Methods Instrum Comput 34:605-612. 
Guillery RW, Sherman SM (2002) Thalamic relay functions and their role in corticocortical communication: generalizations from the visual system. Neuron 33:163-175.

Hallett PE (1978) Primary and secondary saccades to goals defined by instructions. Vision Res 18:1279-1296.

Hamilton JD (1994) Time series analysis. Princeton: Princeton UP.

Handwerker DA, Ollinger JM, D’Esposito M (2004) Variation of BOLD hemodynamic responses across subjects and brain regions and their effects on statistical analyses. Neuroimage 21:1639-1651.

Huttenlocher PR (1979) Synaptic density in human frontal cortex: developmental changes and effects of aging. Brain Res 163:195-205.

Ide JS, Li CS (2010) A cerebellar thalamic cortical circuit for error-related cognitive control. Neuroimage. Advance online publication. Retrieved October 6, 2010. doi:10.1016/j.neuroimage.2010.07.042.

Kang HC, Burgund ED, Lugar HM, Petersen SE, Schlaggar BL (2003) Comparison of functional activation foci in children and adults using a common stereotactic space. Neuroimage 19:16-28.

Kawamura S, Sprague JM, Niimi K (1974) Corticofugal projections from the visual cortices to the thalamus, pretectum and superior colliculus in the cat. J Comp Neurol 158:339-362.

Kerns JG, Cohen JD, MacDonald AW 3rd, Cho RY, Stenger VA, Carter CS (2004) Anterior cingulate conflict monitoring and adjustments in control. Science 303:1023-1026.

Konishi S, Nakajima K, Uchida I, Sekihara K, Miyashita Y (1998) No-go dominant brain activity in human inferior prefrontal cortex revealed by functional magnetic resonance imaging. Eur J Neurosci 10:1209-1213.

Konishi S, Donaldson DI, Buckner RL (2001) Transient activation during block transition. Neuroimage 13:364-374.

Kunimatsu J, Tanaka M (2010) Roles of the primate motor thalamus in the generation of antisaccades. J Neurosci 30:5108-5117.

Lewis CM, Baldassarre A, Committeri G, Romani GL, Corbetta M (2009) Learning sculpts the spontaneous activity of the resting human brain. Proc Natl Acad Sci U S A 106:17558-17563.

Luna B, Sweeney JA (2004) The emergence of collaborative brain function: fMRI studies of the development of response inhibition. Ann NY Acad Sci 1021:296-309.

Luna B, Thulborn KR, Strojwas MH, McCurtain BJ, Berman RA, Genovese CR, Sweeney JA (1998) Dorsal cortical regions subserving visuallyguided saccades in humans: an fMRI study. Cereb Cortex 8:40-47.

Luna B, Thulborn KR, Munoz DP, Merriam EP, Garver KE, Minshew NJ, Keshavan MS, Genovese CR, Eddy WF, Sweeney JA (2001) Maturation of widely distributed brain function subserves cognitive development. Neuroimage 13:786-793.

Luna B, Garver KE, Urban TA, Lazar NA, Sweeney JA (2004) Maturation of cognitive processes from late childhood to adulthood. Child Dev 75:1357-1372.

Luna B, Padmanabhan A, O'Hearn K (2010) What has fMRI told us about the development of cognitive control through adolescence? Brain Cogn 72:101-113.

Menon RS, Luknowsky DC, Gati JS (1998) Mental chronometry using latency-resolved functional MRI. Proc Natl Acad Sci U S A 95:1090210907.

Merriam EP, Colby CL, Thulborn KR, Luna B, Olson CR, Sweeney JA (2001) Stimulus-response incompatibility activates cortex proximate to three eye fields. Neuroimage 13:794-800.

Miller EK, Cohen JD (2001) An integrative theory of prefrontal cortex function. Annu Rev Neurosci 24:167-202.

Miller LM, Sun FT, Curtis CE, D’Esposito M (2005) Functional interactions between oculomotor regions during prosaccades and antisaccades. Hum Brain Mapp 26:119-127.

Munoz DP, Everling S (2004) Look away: the anti-saccade task and the voluntary control of eye movement. Nat Rev Neurosci 5:218-228.

Müri RM, Heid O, Nirkko AC, Ozdoba C, Felblinger J, Schroth G, Hess CW (1998) Functional organisation of saccades and antisaccades in the frontal lobe in humans: a study with echo planar functional magnetic resonance imaging. J Neurol Neurosurg Psychiatry 65:374-377.

Olesen PJ, Nagy Z, Westerberg H, Klingberg T (2003) Combined analysis of
DTI and fMRI data reveals a joint maturation of white and grey matter in a fronto-parietal network. Brain Res Cogn Brain Res 18:48-57.

Paus T, Petrides M, Evans AC, Meyer E (1993) Role of the human anterior cingulate cortex in the control of oculomotor, manual, and speech responses: a positron emission tomography study. J Neurophysiol 70:453-469.

Paus T, Zijdenbos A, Worsley K, Collins DL, Blumenthal J, Giedd JN, Rapoport JL, Evans AC (1999) Structural maturation of neural pathways in children and adolescents: in vivo study. Science 283:1908-1911.

Pierrot-Deseilligny Ch, Müri RM, Nyffeler T, Milea D (2005) The role of the human dorsolateral prefrontal cortex in ocular motor behavior. Ann NY Acad Sci 1039:239-251.

Rakic P, Bourgeois JP, Eckenhoff MF, Zecevic N, Goldman-Rakic PS (1986) Concurrent overproduction of synapses in diverse regions of the primate cerebral cortex. Science 232:232-235.

Ringo JL, Doty RW, Demeter S, Simard PY (1994) Time is of the essence: a conjecture that hemispheric specialization arises from interhemispheric conduction delay. Cereb Cortex 4:331-343.

Roebroeck A, Formisano E, Goebel R (2005) Mapping directed influence over the brain using Granger causality and fMRI. Neuroimage 25:230242 .

Rubia K, Smith AB, Brammer MJ, Taylor E (2003) Right inferior prefrontal cortex mediates response inhibition while mesial prefrontal cortex is responsible for error detection. Neuroimage 20:351-358.

Rubia K, Smith AB, Taylor E, Brammer M (2007) Linear age-correlated functional development of right inferior fronto-striato-cerebellar networks during response inhibition and anterior cingulate during errorrelated processes. Hum Brain Mapp 28:1163-1177.

Rushworth MF, Walton ME, Kennerley SW, Bannerman DM (2004) Action sets and decisions in the medial frontal cortex. Trends Cogn Sci 8:410-417.

Sakai K (2008) Task set and prefrontal cortex. Annu Rev Neurosci 31: $219-245$.

Schall JD, Boucher L (2007) Executive control of gaze by the frontal lobes. Cogn Affect Behav Neurosci 7:396-412.

Schwartz G (1978) Estimating the dimension of a model. Ann Stat 5: $461-464$.

Seth AK (2010) A MATLAB toolbox for Granger causal connectivity analysis. J Neurosci Methods 186:262-273.

Sridharan D, Levitin DJ, Menon V (2008) A critical role for the right frontoinsular cortex in switching between central-executive and default-mode networks. Proc Natl Acad Sci U S A 105:12569-12574.

Stevens MC, Kiehl KA, Pearlson GD, Calhoun VD (2007) Functional neural networks underlying response inhibition in adolescents and adults. Behav Brain Res 181:12-22.

Stufflebeam SM, Witzel T, Mikulski S, Hämäläinen MS, Temereanca S, Barton JJ, Tuch DS, Manoach DS (2008) A non-invasive method to relate the timing of neural activity to white matter microstructural integrity. Neuroimage 42:710-716.

Sweeney JA, Luna B, Berman RA, McCurtain BJ, Voyvodic J, Thulborn KR (1996) Functional MRI studies of reflexive and voluntary saccadic eye movements. Neuroimage 3:420.

Talairach J, Tournoux P (1988) Co-planar stereotaxic atlas of the human brain. Stuttgart, Germany: Thieme.

Velanova K, Wheeler ME, Luna B (2008) Maturational changes in anterior cingulate and frontoparietal recruitment support the development of error processing and inhibitory control. Cereb Cortex 18:2505-2522.

Velanova K, Wheeler ME, Luna B (2009) The maturation of task set-related activation supports late developmental improvements in inhibitory control. J Neurosci 29:12558-12567.

Visscher KM, Miezin FM, Kelly JE, Buckner RL, Donaldson DI, McAvoy MP, Bhalodia VM, Petersen SE (2003) Mixed blocked/event-related designs separate transient and sustained activity in fMRI. Neuroimage 19:16941708.

Yakovlev PI, Lecours AR, Minkowski A (1967) The myelogenetic cycles of regional maturation of the brain. In: Regional development of the brain in early life, pp 3-70. Oxford: Blackwell Scientific. 